\title{
HYDRAULIC SYSTEMS SAFETY BY REDUCING OPERATION AND MAINTENANCE MISTAKES
}

doi: $\quad 10.2478 /$ czoto-2019-0089

Date of submission of the article to the Editor: $30 / 11 / 2018$

Date of acceptance of the article by the Editor: 05/02/2019

\author{
Andrzej Sobczyk ${ }^{1}$ - orcid id: 0000-0002-5697-0781 \\ Janusz Pobędza ${ }^{2}$ - orcid id: 0000-0001-7218-4935 \\ ${ }^{1}$ Cracow University of Technology, Faculty of Mechanical Engineering Poland, \\ andrzej.sobczyk@mech.pk.edu.pl \\ ${ }^{2}$ Cracow University of Technology, Faculty of Mechanical Engineering Poland
}

\begin{abstract}
The subject of the article is concern towards hydraulic systems safety improvement by elimination or/and reduction the possible mistakes which could be the reason of operator accidents and damage of the machine and surroundings. The most typical situation which could be present during hydraulic system operation and maintenance have been analysed and classified to help understand its correlation with safety. Finally each of specified danger situation during system operation and/or maintenance contents rules and warning advice to avoid safety risk.
\end{abstract}

Keywords: hydraulic systems, safety, maintenance

\section{INTRODUCTION}

The Hydraulic drive and control systems are popular on many types of mechanical equipment because they reduce the need for complex mechanical linkages and allow remote control of numerous operations. Such hydraulic systems are used in numerous types of operation like lifting loads and changing the position of heavy components such as a combine header or bulldozer blade and assisting steering, driving and braking mobile machines. An example of a hydraulic system of lifting the excavator boom is shown in Fig.1 (Sobczyk, 2011).

To use hydraulic power, hydraulic systems must store fluid under high pressure, typically $25 \mathrm{MPa}$ up to $40 \mathrm{MPa}$ in mobile and/or stationary machines. Due to energy saving and ensuring continuity of work many systems store hydraulic energy in accumulators. Even though the pump may be stopped or an implement disconnected, the system is still under pressure high pressure. And must be said here that the hydraulic fluid (mainly mineral or synthetic oil) fluid under tremendous pressure is hot and some of the properties of hydraulic fluids are toxic too. To work on such a hazardous system safely, applying safety rules are crucial and mandatory. General principles and safety requirements regarding systems and hydraulic components are included in the standards, in particular in the standard with the symbol PN-EN ISO 4413, which is a norm harmonized with the Machinery Directive 2006/42 / EC. 
Generally, it can be assumed, that there is no such thing as zero-risk although the equipment used is of very good quality. The respect of the security instructions takes on its full meaning here. Each user must have a safe and adopted approach to the use of hydraulic systems. You may be burned or suffer bruises, cuts or abrasions, even worse, a septicemia due to an injection of high-pressure oil. If this happens, take it seriously even if you do not feel pain (ID System, 2018).

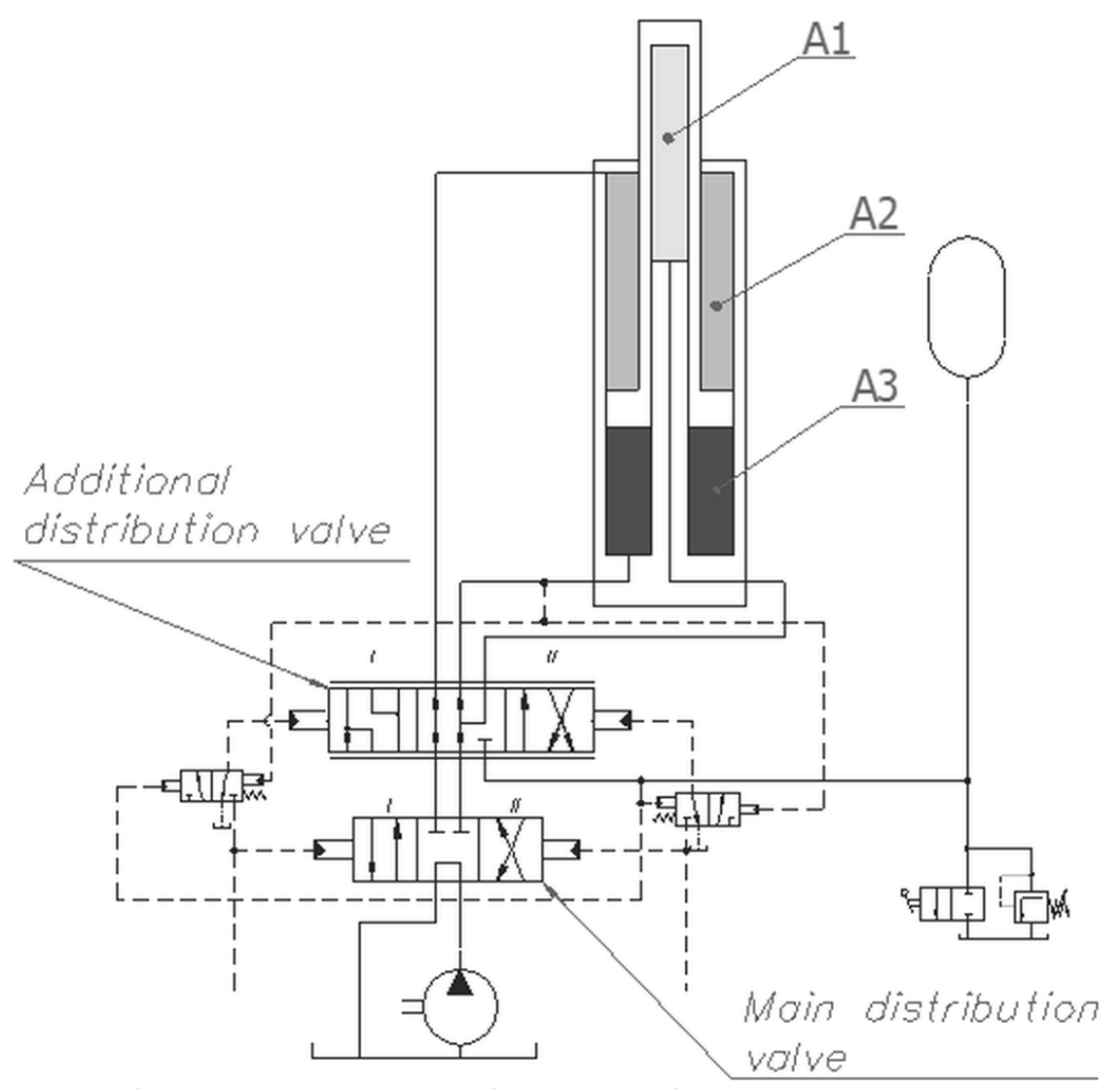

Fig.1. Diagram of the hydraulic system of the boom lifting mechanism, allowing, by using a high-pressure hydraulic accumulator, for energy recuperation (Sobczyk, 2011)

\section{TYPES OF ACTIVITIES IN STARTING, OPERATING AND MAINTENANCE HIGH- PRESSURE HYDRAULIC SYSTEMS IN THE CONTEXT OF DIRECT MACHINE AND INDIRECTLY HUMAN SECURITY}

In particular, important issues in this context will be the correct performance of specific activities and behavior in situations of threat from the system or its failure. We can distinguish among others these activities concern: oil and filter change, overheat of the oil in the system above the acceptable temperature, use the wrong liquid, use the wrong filters and their location, the first system start-up, the behavior incompatible with the operating instructions and the lack of basic technical knowledge range of hydraulic drives.

\subsection{Applying the right fluid to the hydraulic system}

The working fluid, popularly called oil, is really the most important component of any hydraulic (hydrostatic) system. Its function is not only primary task which is power transfer throughout the hydraulic system but also the very crucial task which is lubricating of the movable parts of the components, like pumps, valves, motors, and 
cylinders. Working fluids also help to cool the system as well as help in cleaning it by transporting solid particles to the filters. It's this first dual role which makes viscosity the most important property of the oil - because it significantly affects both machine performance and service life.

\subsection{Start up the system}

This first start up the new or after "oil service" hydraulic system must be run under the very strict procedure. It is because, if the right steps aren't followed during initial startup, hydraulic components and/or whole system can be seriously damaged. Furthermore, in some cases they may work correctly for a while, but the harm done at start-up dooms them to premature failure. Technical literature reports a huge number of these types of failures which wrongly end up as warranty claims by hydraulic equipment owners. And it's also frustrating for everyone concerned - because they could be almost totally preventable. It could be assumed that there are two parts to getting this right, first - knowing what to do; and second - remembering to do it. If we don't know what to do that's one thing. However, if you do know, but forget to do it, well that's soul destroying. For example, we can't pat yourself on the back for filling the pump housing with clean oil when you forgot to open the intake isolation valve before starting the engine. This sort of mistake is easily prevented by using a start-up procedure and checklist even we are convinced that we remember what to do with the machine's hydraulic. Another word, to avoid the consequences of mistake during start up the hydraulic system, never attempt (or allow anyone else to attempt) to re-start a hydraulic machine after changing components without a written checklist which tells exactly what to do, and the order in which to do it in. And precisely speaking what that is here and it has been remembered also - because to be effective, it must be machine specific. The pre-flight checklist for a Boeing Dream Liner is no use at all to a pilot flying an Airbus machine or other manufacturer marks of the airplane.

\subsection{Changing the oil}

It should be remembered that there are only two conditions that necessitate a hydraulic oil change. They are as follows, degradation of the base oil or depletion of the additive package. Should be mentioned here that because there are so many variables that determine the rate at which oil degrades and additives get used up, changing the hydraulic oil on hours in service - without any reference to the actual condition of the oil - is like shooting in the dark. Given the current high price of oil, dumping oil which doesn't need to be changed is the last thing we want to do. And the larger the reservoir the more expensive this mistake. On the other hand, if you continue to operate with the base oil degraded or additives depleted, you compromise the service life of every other component in the hydraulic system. And that's the last thing we would like to have as a result. Taking this into consideration - we can conclude that changing the hydraulic oil on a fixed number of hours in service is a bad idea. In consequence, the only way to know when the oil does need to be changed is through oil analysis. It should be added here, that if oil contents only contamination by particles or water, these contaminants can usually be economically removed using offline filtration. 


\subsection{Changing the filters}

A similar situation (like has been described in chapter 2.3) applies to hydraulic filters changing. If we change them on hours, we're either changing them too early or too late. If we change them early - before all their dirt holding capacity is used up, you're wasting money on unnecessary filter changes. If you change them late - after the filter has gone on bypass, the increase in particles in the oil quietly reduces the service life of every component in the hydraulic system - costing a lot more in the long run and in longer run could damage seriously the components and stop the machine (make it out of order). So, the solution is to change filters when all their dirt-holding capacity is used up - but before the bypass valve opens. This requires a mechanism to monitor the restriction to flow (pressure drop) across the filter element and alert you when this point is reached. A clogging indicator is the crudest form of this device and although better than nothing, continuous monitoring of pressure drop across the filter, on the electronic way, using a differential pressure gauge or transducer is the better solution.

\subsection{Overheating the hydraulic system}

As is commonly known continue to operate an engine that was overheating. The same can be said when the hydraulic system gets too hot. But like an engine, the fastest way to destroy hydraulic components, seals, hoses and the oil itself is hightemperature operation. The question is how hot is too hot for a hydraulic system? The answer is that it mainly depends on the viscosity - and viscosity index (rate of change in viscosity with temperature) of the oil used, and the type of hydraulic components in the system. Physical phenomena in the hydraulic causes that when oil's temperature increases its viscosity decreases. So a hydraulic system is operating too hot when it reaches the temperature at which oil viscosity falls below that required lubrication of the components with movable elements. For example, a vane pump requires a higher minimum viscosity than a piston pump. And this is why the type of hydraulic components used also influences the system's safe maximum operating temperature. In that case, the minimum viscosity we should be looking to maintain is 25 centistokes (cSt or $\mathrm{mm}^{2} / \mathrm{s}$ ). Besides the lubrication issue - the importance of which can't be overstated - operating temperatures above $82^{\circ} \mathrm{C}$ damage most seal and hose compounds and accelerate degradation of the oil itself. But for the reasons explained above, a hydraulic system can be running too hot well below temperature limited by the oil parameters (HydraulicSupermarket.com, 2018).

\subsection{Choosing and/or using not proper oil}

As it was mentioned above the oil is the most important component of any hydraulic system, functioning, not only as a lubricant, but also the energy carrier throughout the hydraulic system. From that point of view, it's this dual role makes viscosity the most important property of the oil - because it affects both machine performance and service life. So, when the hydraulic system running too, the viscosity of the oil largely determines the maximum and minimum oil temperatures within which the hydraulic system can safely operate. This is sometimes referred, in its operation documentation, to as the temperature operating window (TOW). It means that if we are using oil with a viscosity that is too high for the climate the machine has to operate in, the oil won't flow properly or lubricate adequately during cold start. On another hand, if we are using use oil with a viscosity that's too low for the prevailing climate, it 
won't maintain the required minimum viscosity, and therefore adequate lubrication function, on the hottest days of the year. But that's not the end of application the wrong oil from viscosity point of view. Within the allowable extremes of viscosity required for adequate lubrication, there's a narrower viscosity band where power losses are minimized. If operating oil viscosity is higher than ideal, more power is lost to fluid friction. If operating viscosity is lower than ideal, more power is lost to mechanical friction and internal leakage, too. So using the wrong viscosity oil not only results in lubrication damage and premature failure of major components - but it also increases the power consumption of the diesel engine or electric motor - two things we don't want. And despite what we might think, we won't always get this right by blindly following the machine manufacturer's oil recommendation. The only way to be certain is to check your machine's actual temperature operating window lies within the allowable temperature operating window - and ideally - within the optimum temperature operating window for the oil you're using.

\subsection{Location of the filter in hydraulic circuit}

There are two critical hydraulic filter locations that do more harm than good and can rapidly destroy the very components they were installed to protect the system. These filter locations, which should be avoided, are the pump inlet, and piston pump and motor case drain lines. If getting maximum pump life is the primary concern here and it should be, then it's far more important for the oil to freely and completely fill the pumping chambers during every intake, than it is to protect the pump from nuts, bolts and $9 / 16$, what could not have place in right manufacturing and assembling hydraulic oil tank, where the pump inlet penetration is a least two inches off the bottom. Research has shown that a restricted intake can reduce the service life of a gear pump by even $56 \%$. It's worse for vane and piston pumps because these designs are less able to withstand the vacuum-induced forces caused by a restricted intake. It can say that hydraulic pumps are not designed to 'suck' the oil. A different set of problems arise from filters installed on the drain lines of piston pumps and motors - but the result is the same as suction strainers - they can reduce service life and cause serious failures in these expensive components.

\section{SAFETY OF THE HYDRAULIC SYSTEM WITH A VIEW OF THE HUMAN}

Taking into consideration content of chapter 2, where the safety of the hydraulic system has been discussed as an effect of proper startup, applied working fluids and its temperature, filtering and general rules of run and maintenance following could be added as a most frequent risk causing by behaviors of the hydraulic system operators. To avoid most of the met risk to human health and life the following rules should be introduced to the practice:

- never Experiment and before working with or on any equipment, study the circuit drawings, manuals and instruction for the equipment or machine;

- protect against accidental starting of the machine being worked on by taking such precautions as padlocking the electrical gear, disengaging the clutch or removing the battery straps of an engine;

- check pressure gauges to ensure that the pressure in the system is zero and always consider possible sources of trapped pressure, do not tighten any fitting and/or connectors that are under pressure; 
- never rush, considering the effect before opening or closing hydraulic valves;

- be sure that all parts of the system are in a safe position. Especially remember always block up cylinder held items;

- open all hydraulic lines carefully;

- replace all tubing, hose, fittings and other parts with the identical size and material;

- if a leak in a pipe, hose, fitting or block is discovered, shut down and repair.

- always clean oil spills, which cause the floor very slippery;

- avoid direct contact with hoses, fittings and hydraulic devices when a piece of equipment is running;

- do not attempt to stop a leak with any part of your body;

- do not tighten any fitting that is under pressure;

- some individuals are allergic to hydraulic fluids and should avoid contact with bare skin and especially the eyes;

- always wear safety glasses.

Finally, it should be underlined that bursting pipes seldom are dangerous, although in some cases, oil escaping through a very small hole can penetrate the skin if close contact is made. In no case do not touch any hose that is under pressure with or without gloves because high-pressure hydraulic oil can puncture gloves and skin. It should be added that oil inside the body cannot be cleaned out easily, what complicate treatment and recovery.

\section{CONCLUSION}

Based on literature and experience general conclusions to the hydraulic systems and operating human safety, as follows:

- remember that hydraulic components are not self-priming and self- lubricating.

- don't change the hydraulic oil on hours in service. Change the oil when its additives are used up or the base oil is shot. And the only way to know when this point is reached is to do regular oil analysis,

- don't change hydraulic filters on hours in service. Change the filters when all their dirt holding capacity is used up, but before they go on bypass. And the only way to know when this point is reached is to monitor the pressure drop across the filter element using a clogging indicator (that works!), or better still, a differential pressure gauge.

- never let your hydraulic equipment operate above the specified temperature at which viscosity falls to $10 \mathrm{cSt}$,

- you must define the temperature operating window for the viscosity grade and the viscosity index of the hydraulic oil you're currently using. And then make sure your machine operates within it at all times!

- there are four fatal conditions that high pressure hydraulic can create. There could act as injection injuries, dangerous properties of the fluid (toxic), burns caused by contact with the hot fluid, injuries caused by other material movements (explosion, whipping hose, etc.)

Similar methodology, related to safety-preserving behavior, may be useful during a design - as recommended by the Taguchi robust design (Phadke, 1989) - of hydraulic for heavy duty machines (Lisowski and Filo, 2017). Additionally, it may require further, advanced numerical simulation (Domagała et al., 2018a; Domagała et al., 2018b; Fabis-Domagala et al., 2018), sometimes requiring a large computing 
infrastructure (Singh et al., 2016; Singh et al., 2017), including a parametric (Styrylska and Pietraszek, 1992; Kozien, 2009) and a non-parametric estimation (Dwornicka et al., 2017; Pietraszek et al., 2017). To achieve maximum effectiveness, it is recommended to use a design of experiment methods like e.g. in biotechnology (Skrzypczak et al., 1994), phytochemistry (Skrzypczak-Pietraszek and Pietraszek, 2009; Skrzypczak-Pietraszek et al., 2018a; Skrzypczak-Pietraszek et al., 2018b) or materials science (Kuscer et al., 2007; Korzekwa et al,. 2016). Suggested improvements should be reflected in related management systems (Ulewicz et al., 2013; Ulewicz, 2016; Pacana and Ulewicz, 2017; Maszke et al., 2018).

\section{REFERENCES}

Domagala, M., Momein, H., Domagala-Fabis, J., Filo, G., Kwiatkowski, D., 2018a, Simulation of Cavitation Erosion in a Hydraulic Valve. Mater. Res. Proc. 5, 1-6.

Domagala, M., Momeni, H., Domagala-Fabis, J., Filo, G., Krawczyk, M., 2018b, Simulation of Particle Erosion in a Hydraulic Valve. Mater. Res. Proc. 5, 17-24.

Dwornicka, R., Radek, N., Krawczyk, M., Osocha, P., Pobedza, J., 2017. The Laser Textured Surfaces of the Silicon Carbide Analyzed with the Bootstrapped Tribology Model. Metal 2017: $26^{\text {th }}$ Int. Conf. Metallurgy and Materials, Ostrava, Tanger, 12521257.

Fabis-Domagala, J., Filo, G., Momeni, H., Domagala, M., 2018. Instruments of identification of hydraulic components potential failures. MATEC Web Conf., 183 (2018) 03008.

HydraulicSupermarket.com, How a little mistake cost a hydraulic equipment owner $\$ 86,165$ a year!. https://www.hydraulicsupermarket.com/the-right-oil.html [date: 08.11.2018]

ID System, Understanding hydraulic risks and preventing accidents. https://www.idsystem-didactic.com/en/hydraulic-safety/ [date: 08.11.2018]

Korzekwa, J., Bara, M., Pietraszek, J., Pawlus, P., 2016. Tribological behaviour of $\mathrm{Al}_{2} \mathrm{O}_{3}$ /inorganic fullerene-like $\mathrm{WS}_{2}$ composite layer sliding against plastic. Int. J. Surf. Sci. Eng., 10, 570-584.

Kozien, M.S., 2009. Acoustic intensity vector generated by vibrating set of small areas with random amplitudes. J. Theor. App. Mech.-Pol. 47, 411-420.

Kuscer, D., Korzekwa, J., Kosec, M., Skulski, R., 2007. A- and B-compensated PLZT x/90/10: Sintering and microstructural analysis. J. Eur. Ceram. Soc. 27, 4499-4507.

Lisowski, E., Filo, G., 2017. Analysis of a proportional control valve flow coefficient with the usage of a CFD method. Flow Meas Instrum 53, 269-278.

Maszke, A., Dwornicka, R., Ulewicz, R., 2018. Problems in the implementation of the lean concept at a steel works - Case study. MATEC Web Conf., 183, art. 01014.

Pacana, A., Ulewicz, R., 2017. Research of Determinants Motiving to Implement the Environmental Management System. Pol. J. Manag. Stud. 16, 165-174.

Phadke, M.S., 1989. Quality Engineering using Robust Design. Prentice Hall, Englewood Cliffs, USA.

Pietraszek, J., Szczotok, A., Kolomycki, M., Radek, N., Kozien, E., 2017. Nonparametric assessment of the uncertainty in the analysis of the airfoil blade traces. Metal 2017: $26^{\text {th }}$ Int. Conf. Metallurgy and Materials, Ostrava, Tanger, 1412-1418.

Singh, B. et al., 2016. Study of doubly strange systems using stored antiprotons. Nucl. Phys. A 954, 323-340. 
Singh, B. et al., 2017. Feasibility study for the measurement of pi $N$ transition distribution amplitudes at (P)over-barANDA in (P)over-barp $->\mathrm{J} / p s i$ pi(0). Phys. Rev. D. 95, 3, 25 p., 032003.

Skrzypczak, L., Skrzypczak-Pietraszek, E., Lamerzarawska, E., Hojden, B., 1994. Micropropagation of Oenothera-Biennis $L$ and an Assay of Fatty-Acids. Acta Soc. Bot. Pol. 63, 173-177.

Skrzypczak-Pietraszek, E., Pietraszek, J., 2009. Phenolic acids in in vitro cultures of Exacum affine Balf. f. Acta Biol. Cracov. Bot., 51, 62-62.

Skrzypczak-Pietraszek, E., Piska, K., Pietraszek, J., 2018a. Enhanced production of the pharmaceutically important polyphenolic compounds in Vitex agnus castus $L$. shoot cultures by precursor feeding strategy. Eng. Life Sci., 18, 287-297.

Skrzypczak-Pietraszek, E., Reiss, K., Zmudzki, P., Pietraszek, J., 2018b. Enhanced accumulation of harpagide and 8-O-acetyl-harpagide in Melittis melissophyllum L. agitated shoot cultures analyzed by UPLC-MS/MS. PLoS ONE 13, e0202556.

Sobczyk, A., 2011. Improvement of Hydraulic System Efficiency by Means of Energy Recuperation. Wyd. Politechniki Krakowskiej, Kraków, Poland.

Styrylska, T., Pietraszek, J., 1992. Numerical Modeling of Non-Steady-State Temperature-Fields with Supplementary Data. Z. Angew. Math. Mech. 72, T537T539.

Ulewicz, R., 2016. Quality Management System operation in the woodworking industry. Int. Conf. Path Forward for wood products: a global perspective. Proc. of Sci. Papers, Zagreb, WOODEMA 51-56.

Ulewicz, R., Selejdak, J., Borkowski, S., Jagusiak-Kocik, M., 2013. Process management in the cast Iron foundry. Metal 2013: $22^{\text {nd }}$ Int. Conf. Metallurgy and Materials, Ostrava, Tanger, 1926-1931. 